\title{
Practice, Opportunities and Challenges of Student Centered Approach in Teaching at Different Field Of Specialization: A Case of Oromia Zone, Bati Woreda Second Cycle Primary Schools
}

\begin{tabular}{|c|c|}
\hline \multirow{2}{*}{\multicolumn{2}{|c|}{$\begin{array}{c}\text { Asrat Dagnew }{ }^{\mathbf{1}^{*}} \text { and Kibru Engida } \\
{ }^{1} \text { Bati Woreda Education Office, Post Box No: } 327 \text { Oromia, Ethiopia } \\
{ }^{2} \text { Faculty of Education and Behavioral Science, Bahir Dar University, Post Box No: 79, Bahir Dar, Ethiopia }\end{array}$}} \\
\hline & \\
\hline Abstract & Article Information \\
\hline $\begin{array}{l}\text { The purpose of this study was to analyzing the status of teachers' practices, the } \\
\text { opportunities and challenges of implementing student centered approach in teaching at } \\
\text { different field of specializations. To conduct the study, descriptive survey method was } \\
\text { employed. It was carried out in the Oromia zone of Bati woreda. Among } 50 \text { second cycle } \\
\text { primary schools of Bati Worda, } 15 \text { second cycle primary schools were selected by using } \\
\text { Simple random sampling technique. Cluster sampling was employed to select prospective } \\
\text { teachers (142). Thus, all of the teachers in the selected second cycle primary level } \\
\text { schools } 39 \text { natural sciences, } 22 \text { mathematics, } 34 \text { social sciences, and } 47 \text { language } \\
\text { department teachers were included in sampling. The main instrument of data collection } \\
\text { was questionnaire. It was also substantiated with interview and observation. Then, the } \\
\text { data were analyzed using, one sample t-test, ANOVA, mean and percentage. The finding } \\
\text { of the study revealed that the magnitude of practicing student centered in the second } \\
\text { cycle primary schools was found to be low. There is not significance difference in utilizing } \\
\text { student-centered approach as function of teachers' field of specializations. The one to five } \\
\text { organizations of students, the student-text books ratios, the preparation of text-books, } \\
\text { pre-service training of teachers and teachers professional development program } \\
\text { (induction and continuous professional development) were the major opportunities for } \\
\text { implementing student-centered approach. On the other hand, lack of willingness of both } \\
\text { the students and the parents to learning; teachers' tendency to traditional lecture method, } \\
\text { lack of teachers' commitments, shortage of time and shortage of instructional materials } \\
\text { were the major challenges affect the implementation of student centered approach in the } \\
\text { woreda. Finally, the recommendations were forwarded based on the major findings so as } \\
\text { to minimize and gradually solve the problems encountered in effective implementation of } \\
\text { student centered approach. } \\
\text { Copyright@2015 STAR Journal, Wollega University. All Rights Reserved. }\end{array}$ & $\begin{array}{l}\text { Student- centered approach } \\
{ }^{*} \text { Corresponding Author: } \\
\text { Asrat Dagnew } \\
\text { E-mail: } \\
\text { asratboza@yahoo.com }\end{array}$ \\
\hline
\end{tabular}

\section{INTRODUCTION}

These days, people are focusing towards education in order to improve their lives and pave the way for social order and economic development on the ground. Progress in education is essential for fast and sustainable development, environmental protection, improvement in maternal and child health, and participation in democratic, social and political processes. People who have access to education also practice their right better than those who have not. Education is also currently becoming an important contributor to national economic growth. Education enabled the society to have civilized and educated manpower. That is why practical evidence suggests that educational investment has been one of the most important factors contributing to economic growth in both developed and developing countries (Derebssa, 2006).
In the modern world, there is a shift from learning that capitalizes on memorization and rote learning of isolated bites and pieces of information, primarily for the purpose of passing examination, to learning that emphasizes understanding, making connection in the world around us, collecting information, using and communicating in active manner (Lue, 2000). This intention invites a shift from teacher centered to student centered in teaching. This shift was required because, memorizing facts and bits of knowledge is not effective learning and does not prepare the learner to understand their environment or function in it effectively. To put differently, teacher centered approach doesn't prepare the learner to understand and participate in complex world. However, in student-centered approach the purpose of education is not to ensure success in exam. It is rather to help the students' learn what is useful in their life and to develop the individuals' ability to learn independently, to enjoy 
learning and continue to learn throughout life (Margaret, 1988).

Therefore, employing student-centered approach of teaching becomes very crucial, in order to produce independent, competent and practice oriented graduates of the school. Research and experience show that the best-designed student-centered learning is more effective than teacher centered method of teaching. For instance, Peter et al. (2002) indicated that student taught by student centered curricula are superior to those taught by teachercentered approach in their education, long term retention of knowledge and motivation for learning.

The student-centered method is based on the fact that students who are given the freedom to explore areas based on their personal interests, and who are accompanied in their striving for solutions by a supportive understanding facilitator, not only achieve high academic results but also experience and increase in personal values, such as flexibility, self confidence, social skills and problem solving capacity. In the Ethiopian context the New Education and Training policy of Ethiopia emphasizes the development of problem solving capacity and culture in the content of education, curriculum structure and approach, focusing on the acquisition of scientific knowledge and practicum (T.G.E, 1994:4).

Even though student centered approach is widely accepted, and given due attention by our National Education and Training Policy and helps to prepare learners to solve problems, makes them creative and use information from their environment and other sources to make a better life for them, the society and for the country, its proper implementation is doubtful. Teaching styles in many places, however, remain traditional, teacher-centered and fairly rigid or even authoritarian (Carron and Chau, 1996; Amenu, 2005). There is a scarcity of research on how the teaching process affects quality of education in Oromia Zone of Bati woreda. Always, in every meeting the educational officers describe the cause of the quality of an educational system in terms of 'input' such as student -teacher ratios, student- text book ratios, student-class room ratios.

According to Lue (2000:10) the young learner learns best when he or she can connect what is being learned with his or her own life and this makes learning meaningful. In relation to this, the New Education and Training policy and the subsequent school curriculum focuses on the modern method of teaching that propagates learner centered method. Ambaye (1992:2) stated that, in Ethiopia the new curriculum at schools (1-8) is now under way and calls for emphasis on intellectual stimulation, practical application and student centered learning. This implies that, the curriculum development, and instructional materials which were based on teacher centered method in the past and instructional methods which was dominated by passive learning which encourages pouring of information in the brain of the learner is being changed.

Even though the student-centered approach is theoretically advocated, in practice the teacher centered method may predominate in most cases. In addition, regarding teaching learning process in primary schools, pollard et al. (2000) indicated that, teaching in today's primary schools is very much a matter of teachers talking and children listening. Classroom practices in primary schools are intense and more teachers controlled. Students are less autonomous in their use of space and time and in their choice of activities. Though, the utilization of student centered approach is highly advocated, the researcher is doubtful that whether the paradigm shift which was introduced recently in the teaching learning process is well understood and implemented by the teachers and concerned officials to make it practical.

Research findings consistently have shown that the traditional lecture, demonstration and question and answer methods, in which teachers talk and students listen dominate in schools. These directions naturally do not encourage students to be actively participating in teaching-learning. But practically, all learning is inherently active and that students can learn to the extent that they are actively involved in it. According to Daniel (2006) and Nigussu (2009) despite the strong criticism on the teaching learning process in most schools in Ethiopia persisted to be teacher dominated. Most classes are characterized by a situation where students are made to listen to their teachers and copy notes from the blackboard. Thus, it is very essential to conduct research by taking Oromia zone of Bati woreda, to investigating the practices, opportunities and challenges of studentcentered approach implementation by taking second cycle primary schools in focus.

Thus, this study was aim at analyzing the status of teachers practice, the opportunities and challenges of implementing student centered approach in teaching at different field of specializations, in case of Oromia Zone of Bati wereda second cycle primary level schools. Based on the above facts the purposes of this study is to assess the status of teachers practice towards student-centered approach practices, to investigate whether there is difference or not in using student centered approach in teaching at different field of specializations, to assess the major opportunities for implementing student-centered approach and to Identify the major challenges that entangle the implementation of student-centered approach

\section{MATERIALS AND METHODS}

The purpose of this study was to explore the practices, opportunities and challenges of student- centered approach in teaching at different field of specializations in second cycle primary schools of Bati woreda. Thus, descriptive survey method was employed. This is because it helps to explain and investigate what is going on at present. In addition to this, this design is useful to examine through which opinions, attitudes, suggestions for educational practices can be obtained.

\section{The Sources of Data}

The main sources of data for this study were second cycle primary school teachers of Bati woreda. The reason is that they are basically responsibly to practice student centered approach in their teaching. It is the teacher who sets, the sage and conducts and guides life in the classroom. So that they have a power to observe the practice as well as opportunities and challenges of implementing student centered approach. 
Population, Sample and sampling Techniques

According to the information obtained from Bati woreda education office, Bati woreda has 26 rural kebels. There are 50 second cycle primary level schools. On condition that the teachers are concerned, there are (130 natural science teachers, 59 mathematics teachers, 66 social studies teachers, 160 language teachers) in Bati woreda. Of 50 second cycle primary level schools of the Bati woreda, 15 schools were selected through simple random sampling. This constitutes thirty percent. As far as the attendants of the research are concerned, all of the teachers in the sample 15 schools were selected by cluster sampling. As the result, 39 natural sciences, 22 mathematics, 34 social sciences, and 47 languages second cycle primary level teachers in the selected schools were included in sampling.

\section{Instruments and Procedures of Data Collection}

Three main instruments of data collection namely: questionnaire, classroom observation and interview were used in the study.

The researcher was followed three steps in collecting the data for the study. First, relevant literature was review so as to get adequate information on the topic. Second, basic research questions were formulated, which helped to show the direction of the study. Third, data gathering tools were adapt and the necessary questions have been set. Then the questionnaire was administer and gathered by the researcher and an assistant. Lastly, the interview and observation were also making. The observation was made in 3 schools; 15 classes. It was taken $35-40$ minutes, and made by the researcher. Similarly, the interview was made with 12 teachers from the observed schools.

\section{Techniques of Data Analysis}

Based on the instruments the data were organized, coded and analyzed using one sample t-test, ANOVA, mean and percentage. In addition to this, the data obtained through observation and interviews were analyzed using descriptive and narrative qualitative approaches. In order to analysis the status of teacher practice about student centered approach one sample ttest was used. The data were relatively compared subject wise; finally ANOVA was used to check whether the existence of significance difference among different field of specializations in implementing student centered approach. Furthermore, percentage was used to analysis the opportunities and challenges of implementing student centered approach.

\section{RESULTS}

The Status of Teachers' Practice in Implementing Student-Centered Approach

As shown in table 1 the whole calculated t-results of data obtained from respondents regarding to the status of the teachers practice about student centered approach is 13.063. That means there is statistically significant difference in between the observed mean and expected mean value of the teachers practices in implementing student centered approach in all four selected teachers field of specializations. Aggregately the observed mean value of 31.64 is below the expected mean value of 37.5 . This one sample t-test result disclosed that the teachers were not practice about student centered approach as what is expected from them. Hence, the result revealed that the teachers practicing student centered approach in the second cycle primary schools was found to be very low.

This shows that the teachers follow prescribed syllabus and they are more authoritarian. However according to Amare(2000) the role of the teacher in the learner centered method will be changed to managerial than authoritarian. That is, teachers are expected to facilitate student learning and do so by encouraging student activities and student performance and by discouraging teacher's performance in the classroom. Similarly, according to Lowry (1989), as cited in Derebsa (2006), in learner centered students should participate to diagnose their learning needs, select and implement learning strategies and evaluate learning outcomes. So, assessment tools are learner determined.

Table 1: Response of the teachers' related to the status of teachers' practices about student centered approach by one sample t-test

\begin{tabular}{llcccccc}
\hline No & \multicolumn{1}{c}{ Field of specialization } & $\begin{array}{c}\text { Expected } \\
\text { mean value }\end{array}$ & $\begin{array}{c}\text { Observed } \\
\text { mean value }\end{array}$ & std & t-value & df & 2-tailed \\
\hline 1 & Natural science & 37.5 & 31.64 & 5.062 & 7.031 & 36 & .000 \\
2 & Social science & 37.5 & 31.2 & 3.633 & 10.102 & 33 & .000 \\
3 & Mathematics & 37.5 & 31.15 & 4.824 & 6.188 & 21 & .000 \\
4 & Languages & 37.5 & 32.19 & 6.647 & 5.667 & 46 & .000 \\
& $\begin{array}{l}\text { The status of teachers practice in implementing } \\
\text { student centered approach as whole }\end{array}$ & 37.5 & 31.64 & 5.305 & 13.063 & 139 & .000 \\
\hline
\end{tabular}

Significance value at $P<0.05$

The Differences in the Teachers' Utilization of Student-Centered Approach among all Selected Field of Specializations

As shown in table 2, the probability of the F-ratio is 0.303 . Since this value is greater than 0.05 critical values so is not statistically significant. In other words, the mean scores of teachers use of student-centered approach in the sampled departments are homogenous (do not differ). This indicated that there is no statistically significant difference between the four groups (departments) in the utilization of student-centered approach. Supporting this research result Pritchard, (2005) had conducted a research to see the application of active learning methods in different subject matters of the school and he found out that active learning can be applied in all subjects of the school. This implies that if the teachers are willing and have the necessary knowledge and skills of active learning every subject can be taught through active learning techniques regardless of their difference. 
Table 2: The ANOVA summary differences in the teachers' utilization of student centered approach among all selected field of specializations

\begin{tabular}{cccccc}
\hline Source & Sum of Squares & Df & Mean Square & F & Sig. \\
\hline Between Groups & .595 & 3 & .198 & 1.225 & .303 \\
Within Groups & 22.005 & 136 & .162 & \\
Total & 22.600 & 139 & & \\
\hline \multicolumn{6}{c}{ Significance value at $P<0.05$}
\end{tabular}

The Major Opportunities for Implementing StudentCentered Approach

Table 3 indicates that $98(70 \%)$ of respondents replied in which the new education and training policy of Ethiopia helps to prepare learners to solve problems and makes them creative by promoting student centered approach, where as $18(12.9 \%)$ of respondents replied that the new education and training policy of Ethiopia did not promote student centered approach and $24(17 \%)$ of respondents were not completely sure that the new education and training policy of Ethiopia support or encourage the student-centered approach. In general this implies that the new education and training policy of Ethiopia provided a good opportunity for implementing student-centered approach by developing the physical and mental potential and problem solving capacity of individuals. As noted by T.G.E ( 1994:7-8) states that the general objectives of education and training is to develop the physical and mental potential and problem solving capacity of individuals by expanding education and in particular by providing basic education for all. Furthermore, the policy indicates that the general objective and appreciative potential of citizens by appropriately relating education to environment and social needs.

Table 3: Response of the teachers' to the major opportunities for implementing student centered approach in all selected field of specializations

\begin{tabular}{|c|c|c|c|c|c|c|c|}
\hline & \multirow{2}{*}{ Items } & \multicolumn{2}{|c|}{ Yes } & \multicolumn{2}{|c|}{ No } & \multicolumn{2}{|c|}{ Uncertain } \\
\hline & & № & $\%$ & № & $\%$ & № & $\%$ \\
\hline 1 & $\begin{array}{l}\text { Do you think that the new education and training policy of Ethiopia promote } \\
\text { student-centered approach? }\end{array}$ & 98 & 70 & 18 & 12.9 & 24 & 17.14 \\
\hline 2 & $\begin{array}{l}\text { Do the preparations of student text books emphasize one-way communication } \\
\text { than two-way communication? }\end{array}$ & 104 & 74.29 & 27 & 19.3 & 9 & 6.429 \\
\hline 3 & $\begin{array}{l}\text { Do you think that the teachers' professional development program (induction } \\
\text { and continuous professional development) enhances the teachers' skill in } \\
\text { implementing student centered approach? }\end{array}$ & 106 & 75.71 & 25 & 17.9 & 9 & 6.429 \\
\hline 4 & $\begin{array}{l}\text { Do cluster supervisor provide a good opportunities for the implementation of } \\
\text { student-centered approach by supporting the teachers? }\end{array}$ & 94 & 67.14 & 35 & 25 & 11 & 7.857 \\
\hline 5 & $\begin{array}{l}\text { Do you think that the teachers' pre service training at college/institution helps } \\
\text { the teachers in implementing student-centered approach? }\end{array}$ & 103 & 73.57 & 30 & 21.4 & 7 & 5 \\
\hline
\end{tabular}

In the above table, $104(74.3 \%)$ of the respondents replied that the preparation of student text books fosters the implementation of student centered approach. The interview result also prove that the preparation of students text books of second cycle primary schools(grade 5-8) promoted students to solve problems, to inquire, to draw conclusion and communicate about what they have learned because of its more emphasize two way communication than one way communication. On contrary to this $27(19 \%)$ of respondents replied that the preparation of text books did not emphasize two way communication rather, it emphasize one way communication. Whereas $9(6.4 \%)$ of respondents were not sure completely that the student text books more emphasize two way communication or not. In general this finding shows that the preparation of the recent most student text books of second cycle primary schools facilitate the implementation of student centered approach. Hence, they emphasize two way communications than one way communication.

$106(75.7 \%)$ of respondents revealed that teachers' professional development program such as induction and CPD providing a good opportunity to improve the teachers skill for implementing student-centered approach. The informants who selected for interviews also revealed that the induction and CPD Program in which the teachers participated in it at schools level helped them to pinpoint and discuss some problems related to teaching and learning processes with each others. On contrary
$25(17.9 \%)$ of respondents replied that the induction and CPD program in which the teachers currently participating in it were not enhances the teachers' skill for implementing student-centered approach. $9(6.42 \%)$ of the respondents were not sure. As majority of respondents revealed that teachers' professional development (induction and CPD program) in which the teacher participated in it at present time plays a crucial role by enhancing the teachers' skill for implementing the studentcentered approach.

Regarding cluster supervisor, $94(67.1 \%)$ of respondents disclosed that cluster supervisor can provide a good opportunity for implementing student-centered approach. Furthermore, the teachers who were selected for interview informed that although, they have been their own drawbacks in carried out continues supervisory activities and facilitating different teachers' capacity buildings, the cluster supervisor provided good opportunities for implementing student centered approach occasionally focus on providing feedback, mentoring, guiding, redirecting, and giving professional assistance for the purpose of solving problem and improving the teaching and learning environments by observing the classrooms, however $35(25 \%)$ of respondents replied that the presence of cluster supervisor didn't provide good opportunities for implementing student-centered approach where as $11(7.9 \%)$ of respondents replied uncertain that whether the cluster supervisor promote student centered approach. In generally according to the response of 
majority respondents indicated, committed and skillful cluster supervisor plays a vital role in supporting the teachers to properly implement student-centered method of instruction, supervise teaching methodology, coach teachers, evaluate and monitor instructional activities. Darling-Hammond and Mc Laughlin (1995) cited in Gashaw (2008) pointed out supervisory activities regarding professional development has to enable teachers to become source of knowledge for one another and to learn the important role of colleague and learner.

Totally, the majority $103(73.6 \%)$ of the respondents disclosed that the teachers pre-service training at college provide suitable condition for teachers to implement student-centered approach. However 30(21.4\%) of respondents disclosed that the teachers pre-service training at college didn't benefit them to implement student-centered approach and $7(5 \%)$ respondents disclosed that they were not sure completely that the teachers pre service training helps them for implementing student centered approach.

\section{The Major Challenges that may Face in Implementing Student Centered Approach}

About $98(70 \%)$ respondents' revealed that their tendency to traditional lecture and explanation method challenged the implementation of the student-centered method. According to Silberman (1996) confirmed that during lecturing students' attention decreases with each passing minute. As lecturing appeals only to auditory learners, it tends to promote lower level of learning of factual information. Therefore, it should be known that before student-centered method of instruction becomes an accepted way of thinking, it is certainly difficult and even frustrating for teachers to practice it. On the other hand $42(30 \%)$ of respondents were not accepted tendency to traditional lecture and explanation method that challenged the implementation of the studentcentered method.

As indicated from the above table, $109(77.9 \%)$ of respondents' disclosed that group work among students in the class has resulted in the dependency of the majority on minority. This problem was also discussed during the interview with teachers. They explained that by its nature, active approach enhances cooperative work among learners. But the major problem of group work was most students do not fully contribute to the group in both devotion of time and involvement in the activities. Contrary to this $31(22.1 \%)$ of respondents were not accepted that group work among students in the class has resulted in the dependency of the majority on minority.

Similarly, $80(57.14 \%)$ the respondents replied that they have freedom to do their own work without involvement from others. $60(42.86 \%)$ of respondents still complain that there is intervention from others; they have no freedom to do their own work.

Table 4 indicates that $117(83.57)$ of the respondents replied shortage of time, shortage of finance and unavailability of instructional materials as hindering factors to fully implement student centered method were listed by teachers with varying magnitudes. Similarly, in the interview they explained that they avoid active learning simply because it brings an extra demand in the planning, preparation and evaluation of learning and objectives. On the other hand $23(16.43 \%$ ) of the respondents replied that shortage of time, finance and unavailability of instructional material did not challenge the implementation of student centered approach.

In table 4, 47 (33.57) respondents are in favor of the school culture to promote active learning. However, $93(66.4 \%)$ of respondents replied that the school culture did not promote the use of student-centered method. In most of the schools the researcher conducted interview for teachers and there is no continuous supervision from the school itself.

$50(35.7 \%)$ of respondents replied that educational administrations were giving much attention and support for the teachers to implement student-centered approach. But, $90(64.27 \%)$ of the teachers replied that educational administrations were not providing support for teachers to implement student-centered approach.

Finally, $93(66.4 \%)$ of respondents replied that there were problems related to classrooms to practice studentcentered approach. Whereas $47(33.57 \%)$ of the teacher respondents were against to this item of questionnaire. To substantiate the response gained from questionnaire, the other data gathering method interview and observation were conducted. Regarding problems related to classroom there is shortage of desks, chairs and other infrastructures.

Table 4: Response of the teachers to the major challenges that may face in implementing student centered approach in all selected field of specialization

\begin{tabular}{|c|c|c|c|c|c|}
\hline \multirow{2}{*}{ No } & \multirow{2}{*}{ Items } & \multicolumn{2}{|c|}{ yes } & \multicolumn{2}{|c|}{ No } \\
\hline & & No & $\%$ & No & $\%$ \\
\hline 1 & $\begin{array}{l}\text { Do you think that teachers' tendency to the traditional lecture, and explanation methods has } \\
\text { affected the implementation of student-centered? }\end{array}$ & 98 & 70 & 42 & 30 \\
\hline 2 & $\begin{array}{l}\text { Do you think that group work among students in the class has resulted in the dependency } \\
\text { of the majority on minority? }\end{array}$ & 109 & 77.86 & 31 & 22.14 \\
\hline 3 & Do teachers have the freedom to do their own work without involvement from others? & 80 & 57.14 & 60 & 42.86 \\
\hline 4 & $\begin{array}{l}\text { Is there shortage of time, finance and instructional material to practice student-centered } \\
\text { method to cover the content in the material? }\end{array}$ & 117 & 83.57 & 23 & 16.43 \\
\hline 5 & Does your school culture promote the use of student-centered method? & 47 & 33.57 & 93 & 66.43 \\
\hline 6 & $\begin{array}{l}\text { Do educational administrations provide necessary support towards student -centered } \\
\text { approach? }\end{array}$ & 50 & 35.71 & 90 & 64.29 \\
\hline 7 & Are there problems related to classroom to practice student-centered approach? & 93 & 66.43 & 47 & 33.57 \\
\hline
\end{tabular}

\section{DISCUSSION}

Regarding the status of the teachers practice about student centered approach, the magnitude of the whole calculated t-results of data obtained from respondents is 13.063 in all selected filed of specializations. That means there is statistically significant difference in between the 
observed mean value 31.64 and expected mean value of 37.5 in all four selected teachers field of specializations. It means that the observed mean value is below to that of expected mean value. This result implies that the teachers were not practicing student centered approach as what is expected from them. It also disclosed that the teachers engagements in practicing student centered approach is very little and insufficient. Teachers should design situations that allow students learning by doing. However, the finding of the study revealed that the magnitude of practicing student centered approach in the primary schools second cycle was found to be very low.

Regarding the major opportunities for implementing students approach, majority of respondents (more than $66.14 \%$ ) disclosed that the new education and training policy of Ethiopia, one to five organization of students, the teachers' professional development program (induction, continuous professional development), the student-class room ratios, the student text-books ratios, the cluster supervisor, teachers pre service training and the preparation of text books were provided fertile ground for the teachers to implement student-centered approach. The finding that obtained from interview and observation were also exactly the same to that of the result obtained from questionnaires.

Likely, according to (T.G.E, 1994) in the Ethiopian context, the New Education and Training policy of Ethiopia emphasizes the development of problem solving capacity and culture in the content of education, curriculum structure and approach, focusing on the acquisition of scientific knowledge and practicum. It gives opportunities for active involvement, participation and creativity of students, which in turn necessitates the use of effective pedagogical and psychological approaches to meet the demands of the new generation.

Regarding the major challenges that may face the implementation of student centered approach, the majority of respondents $(63.5 \%)$ revealed that the traditional lecture, explanation, group work among students in the class has resulted in the dependency of the majority on minority, shortage of time to practice student-centered method, shortage of finance, lack of instructional materials (library, laboratory, pedagogical center, class room instruction), unconducive school culture and lack of due attention from educational administrations were the major challenges of implementing student-centered approach. Furthermore, the result from interviews shows that low teachers commitments and awareness, lack of willingness of the students to learn, absenteeism, dropout, lack of student awareness' towards the advantageous of student-centered approach were also the major challenges in implementing student-centered approach.

\section{CONCLUSION}

The main purposes of the study was to analyzing the status of teachers practices, the opportunities and challenges of implementing student centered approach in teaching at different field of specializations, a focus to Oromia Zone of Bati woreda second cycle primary schools.

Although the teachers have a good level of understanding on the meaning and advantages of student- centered approach, and have some major opportunities for implementing it, from the study it can be concluded that teachers of second cycle primary schools of Oromia zone of Bati woreda have not practiced about student-centered approach of teaching and learning as expected. On the other hand, the new education and training policy of Ethiopia, the one to five organizations of students, the student-text books ratios, the preparation of text-books, the teachers pre-service training and teachers' professional development program (induction, continuous professional development) were the major opportunities for implementing student-centered approach. On contrary, lack of willingness of both the students and the parents to learning; teachers' tendency to traditional method, lack of teachers' commitments, shortage of time, finance and unavailability of instructional materials were the leading factors affecting the implementation of student centered in the woreda.

\section{Conflict of Interest}

Conflict of interest none declared.

\section{REFERENCES}

Amare Asgedom (2000). Communication and Media Studies in Curriculum Studies: $A$ Study Guide Teaching Material (unpublished).A.A.U.

Ambaye Tsehay (1992). Curriculum Evaluation, Monitoring the Harmony of TTI Syllabus with New primary Level Vizvis Standard Models and New Education Policy. The Ethiopian Journal of Education XIX (I). Addis Ababa: IER.

Amenu Oljira (2005).The implementation of Active Learning Approach in the Teachers' Colleges of Oromia Region. Unpublished Master Thesis. A.A.U.

Carron,G.and Chau, T.N. (1996). The Quality of Primary Schools in Different Development Contexts. Paris. UNESCO.

Daneil Desta (2006). Enhancing Effective Learning through Teachers Peer and Self Reflection in Selected Primary Schools in Ethiopia. Addis Ababa.

Derebssa Dufera Serbessa.(2006).Tension Between Traditional and Modern Teaching-Learning Approaches in Ethiopian Primary Schools. Journal of International Cooperation in Education 9(1): 123-140.

Gashaw Debassu (2008). Supervisory Practice Cluster Primary School Supervisors in Promoting Teachers Competences in West Gojem Administrative Zone. Un published Masters's Thesis, Addis Ababa University, Addis Ababa.

Lue, E. (2000). Implementing the New Curriculum, Issues of Theory and Practice Curriculum Developers and Teacher Education. Mekele: BESSO Project. (unpublished)

Margaret,S.(1988).Theory of Education. London: Allen and unwin.

Nigussu Tilahun (2009). Epistemological Beliefs of Upper Primary School Teachers and Their Teaching Practices. Unpublished. Master Thesis. BDU.

Peter, S. (2002). Problem Based Learning Case Studies Experience and Practice. London: Kogan page Ltd.

Pollard (2000). What Pupil say, Changing Policy and Practice in Primary Education. London: T.J. International.

Pritchard, A. (2005). Ways of Learning: Learning Theories and Learning Styles in Class room. London: David Fulton.

Silberman, M. (1996). Active Learning, 101 Strategies to Teach Any Subject. Boston: Allyn and Bacon.

T.G.E. (1994).The Educational and Training Policy. Addis Ababa: EMPDA. 